\title{
Existirmos... a que será que se destina? Choque ontológico, angústia e coragem de ser na canção Cajuína
}

\author{
Carlos Eduardo Brandão Calvani*
}

\section{RESUMO}

A morte de um ente querido é uma experiência perturbadora que deflagra interrogações diversas sobre o sentido da existência. A ausência de respostas significativas capazes de doar explicação ao inexplicável conduz à angústia. A intensidade da angústia oferece, no seu vácuo, espaço oportuno para a penetração de discursos religiosos que apelam para a autoridade de revelações, iluminações sobrenaturais ou da tradição. Contudo, as religiões não detêm a exclusividade da tematização sobre tais assuntos. A arte, sem a pretensão de oferecer respostas definitivas, sobrenaturais ou transcendentais, também se apresenta como possibilidade para um enfrentamento corajoso da angústia. A partir dessas premissas, o texto oferece uma abordagem do tema da angústia e da coragem-de-ser na canção "Cajuína", de Caetano Veloso.

Palavras-chave: Angústia; Música Popular Brasileira; Tillich; Caetano Veloso; Cajuína

\section{Ontological shock, anguish and the courage to be in the Cajuína song}

\begin{abstract}
The death of a loved one is a disturbing experience that triggers various questions about the meaning of existence. The absence of meaningful responses capable of giving an explanation to the unexplained leads to anguish. The intensity of the anguish offers, in its vacuum, opportune space for the penetration of religious discourses that appeal to the authority of revelations, supernatural illuminations or tradition. However, religions do not retain the exclusivity of the thematization on such subjects. Art, without claiming to offer definitive, supernatural or transcendental answers,
\end{abstract}

* Doutor em ciências da Religião. Professor no Programa de Pós-graduação em Ciências da Religião da Universidade Federal de Sergipe. 
also presents itself as a possibility for a courageous confrontation of anguish. From these premises, the text offers an approach to the theme of anguish and courage-of-being in the song "Cajuína", by Caetano Veloso. Keywords: Anguish; Brazilian Popular Music; Tillich; Caetano Veloso; Cashew liqueur

\section{Introdução}

A morte de um filho, filha, irmã ou irmão, pai ou mãe, cônjuge ou de alguém muito querido é uma das experiências mais perturbadoras que pode sobrevir a uma pessoa. Ela antecipa o vazio da própria morte, inaugurando nos sobreviventes uma existência amputada, da qual foi retirada um dos elementos mais basilares e essenciais. À inicial falta de palavras somam-se memórias que eclodem como que em flashbacks, insistindo em lamentar a abrupta interrupção da comunhão afetiva e de um projeto existencial e a transformar pontos de interrogação em perseverantes reticências.

Mas a experiência da morte nunca vem desacompanhada. Ela deflagra nos sobreviventes outras interrogações, como a do seu próprio destino ou a interrogação pelo sentido da existência humana. Aos poucos, a ausência de respostas significativas capazes de doar explicação ao inexplicável e de configurar uma estrutura de sentido àquilo que "não-tem-sentido-nem-nunca-terá", conduz à angústia. A intensidade da angústia do destino e da morte oferece, no seu vácuo, um espaço oportuno para a penetração de discursos religiosos. É nesse espaço vazio, terra-de-ninguém, na qual os próprios deuses silenciam pela morte de seus filhos, que muitas mensagens religiosas se instalam, apelando para a autoridade de revelações, iluminações sobrenaturais ou da tradição transmitidas por antepassados.

Contudo, as religiões não detêm a exclusividade da tematização sobre tais assuntos. A imensa capacidade humana para superar limites, transcender-se e enfrentar a fragilidade da vida se manifesta, muitas vezes, em formas de expressão não atreladas a sistemas religiosos nem dependentes de compromissos teológicos com discursos oriundos desses sistemas ou a eles vinculados. Isso indica que, para muitas pessoas, os sistemas religiosos não são capazes de capturar suficientemente a complexidade da angústia humana, exceto sob a forma de subserviência 
intelectual a dogmas. Em outras palavras, a arte, sem a pretensão de oferecer respostas definitivas, sobrenaturais ou transcendentais, também se apresenta como possibilidade para um enfrentamento corajoso da angústia.

\section{Morte, destino e falta de sentido - uma fenomenologia da angústia}

Quando escreveu A coragem de ser, Tillich utilizou o termo anxiety (ansiedade) porque o mercado editorial norte-americano na época preferia traduzir Angst por Anxiety, tal como o fizeram Macquarrie e Robinson na primeira tradução de "Ser e Tempo" de Heidegger. Eglê Medeiros, responsável pela tradução do livro de Tillich em português para a Editora Paz e Terra, seguiu o óbvio, traduzindo anxiety por "ansiedade". A mesma palavra foi adotada por Getúlio Bertelli, na $1^{\mathrm{a}}$ edição da Teologia Sistemática. Optamos, porém, por acompanhar as observações de Ênio Müller, responsável pela revisão técnica da nova tradução da Teologia Sistemática publicada em 2005. Resultado de um projeto que envolveu tradutores e pesquisadores da área, a $5^{\mathrm{a}}$ edição revista da Teologia Sistemática no Brasil optou por "angústia". Afinal, nos textos escritos em alemão, Tillich sempre utiliza Angst, em semelhante acepção conceitual a Kierkegaard e Heidegger. Ou seja, embora escrevesse em inglês, Tillich continuava raciocinando em alemão. Além disso, o próprio Tillich, em uma nota da Teologia Sistemática, expressa certo desconforto com o termo anxiety, pelo fato de este ser facilmente confundido psicologizado ao ser confundido com medo, temor e não com a situação ontológica de quem enfrenta o não-ser (TILLICH, 2005, p. 200). Há também certo consenso entre pesquisadores da obra de Tillich no Brasil, de que o termo "angústia" por sua carga conceitual filosófica e teológica é mais coerente com o pensamento de Tillich, tal como ele mesmo o expressa:

Graças a Søren Kierkegaard, a palavra Angst se tornou um conceito central do existencialismo. Ela expressa a consciência de ser finito, de ser uma mescla de ser e não-ser ou de ser ameaçado pelo não-ser. Todas as criaturas são compelidas por essa angústia, pois finitude e angústia são as mesmas coisas. Mas, no ser humano, a liberdade está unida à angústia. Poder-se-ia chamar a liberdade do ser humano de "liberdade na angústia" ou "liberdade angustiada". Essa angústia é uma das forças motrizes da transição da essência à existência. Kierkegaard, sobretudo, usa este 
conceito da angústia para descrever (não para explicar) a transição da essência à existência (TILLICH, 2005, p. 330).

Boa parte do livro A coragem de ser é uma grande fenomenologia da angústia. $\mathrm{O}$ modo como Tillich aborda o tema é um híbrido de Kierkegaard e Heidegger. A angústia não é tratada como um fenômeno psicológico e ôntico. Antes, é tematizada em sua dimensão ontológica. Em termos heideggerianos, o "objeto", por assim dizer, da angústia, é o "completamente indeterminado" (HEIDEGGER, 1986, §30, p.186.), e esse "indeterminado" ou "desconhecido" é de ordem ontológica - o não-ser, aquilo que não pode jamais ser conhecido, objetivado, identificado, tematizado. O que faz emergir a angústia não é a ameaça de qualquer ente específico, ou de qualquer ameaça objetiva, mas exatamente o não-ser, o nada em todo seu potencial angustiante.

Acompanhando Heidegger, Tillich também distingue a angústia do mero temor ou do medo. Medo e temor podem ser contornados e vencidos, mesmo que à custa de medicamentos. O mesmo não acontece com a angústia, por não haver qualquer objeto específico que possa provocá-la. Ela é a negação de todo objeto. É perda de direção, falta de intencionalidade e ausência de sentido (TILLICH, 1972, p. 28-29). A angústia independe de qualquer objeto específico que possa provocá-la, pois o "nada" não é objetificável. Objetos podem ser temidos. Por isso a angústia é ontológica, enquanto o temor é psicológico. A angústia "expressa a finitude desde dentro" (TILLICH, 2005, p. 300). A angústia simplesmente emerge na consciência enquanto percepção da própria finitude e da ameaça do não ser. Tal como em Heidegger, aquilo com o que a angústia se angustia não é um objeto, mas o "nada" não identificável com qualquer ente; um nada nunca efetivamente presente entre a totalidade dos entes, mas que exatamente por isso, desvela a dimensão de vazio e falta de sentido dos entes e do mundo. O "algo" da angústia é seu próprio "nada".

Conforme Paulo Afonso Araújo, "na angústia o ente dissolve-se na sua insignificância e não oferece mais pontos de apoio para qualquer tipo de projeto: o Dasein é remetido unicamente a si mesmo, sem nenhuma possibilidade de desvio ou fuga. A angústia situa o Dasein diante daquilo que ele é propriamente: seu próprio poder ser, seu ser no 
mundo como tal" (ARAÚJO, 2007, p. 8). Assim, angústia, em Heidegger e Tillich, é muito mais do que tristeza ou depressão pela consciência da inevitabilidade da morte. É consciência da tensão básica entre ser e não-ser.

Ao abordar a finitude na perspectiva das principais categorias ontológicas (tempo, espaço, causalidade e substância) Tillich observa que a percepção do tempo como categoria central da finitude instaura a angústia da transitoriedade como antecipação da própria morte. A categoria do espaço também deflagra a angústia, pois ser algo ou alguém implica ter espaço e lutar pela preservação de um espaço físico e social. Contudo, em Tillich, "nenhum ser finito possui um espaço que seja seu de forma definitiva" (TILLICH, 2005, p. 203) e a agudeza dessa percepção equivale a uma insegurança última. A categoria da causalidade também "expressa poderosamente o abismo do não-ser em todas as coisas" (TILLICH, 2005, p. 204) em virtude da incapacidade de todas as coisas de repousar em si mesmas, fazendo emergir na consciência a percepção da própria contingência. $\mathrm{O}$ ser humano não é necessário por si só. É a "angústia diante da falta de necessidade de seu ser. Ele poderia não-ser! Então, por que ele é? E por que deve continuar a ser?" (TILLICH, 1972, p. 205). Tillich reconhece não haver resposta razoável a essa pergunta. Ela só pode ser enfrentada, e este é um ato de coragem - coragem de ser, "apesar de". Em contraste com a causalidade, a categoria da substância busca algo permanente e relativamente estático no fluxo das aparências e das contingências. Mas mesmo aí, o ser humano nada encontra que seja capaz de oferece segurança diante da ameaça do não ser implícita nas mudanças pessoais e sociais.

A existência humana consciente de sua própria finitude, reconhece a ameaça do não-ser como a inevitabilidade da morte e da própria aniquilação no nada. Ontologicamente é a possibilidade sempre presente de ser devorado pelo não-ser. A ameaça do não-ser desdobra-se onticamente em ameaça da morte, do absurdo e da vacuidade de sentido frente ao destino pessoal na vida histórica (e, portanto, frente ao próprio sentido desta vida) e em uma possível continuidade da vida e da autoconsciência pós-morte.

Contudo, a angústia, em Tillich, sempre é um desafio a ser enfrentado com os recursos disponíveis, sejam eles oriundos da esfera 
religiosa ou das artes. Assim, se, por um lado, a angústia desnuda a condição humana, despertando a consciência do vazio da existência, ela também potencializa a criatividade, a coragem e a abertura para além das superficialidades do cotidiano. É no vácuo da angústia que emergem muitos discursos religiosos oferecendo possíveis respostas e algum tipo de enfrentamento à angústia.

\section{0 vácuo no qual as religiões operam - uma tipologia da angústia}

Embora a angústia seja uma só, Tillich em A Coragem de Ser, observa que ela se manifesta em diferentes tipos, de acordo com circunstâncias históricas. Além disso, Tillich oferece ao leitor algumas pistas para compreendermos a emergência ou a preponderância de respostas tipicamente religiosas, através das quais a angústia era enfrentada. Porém, essa tipologia tem apenas efeitos didáticos, pois os "tipos" estão entrelaçados e podem conviver simultaneamente variando o grau de intensidade. Mas em todos sempre está implícita a angústia frente ao não ser, frente à morte, ao absurdo e ao nada.

Em primeiro lugar temos a angústia mais primária, quando o não-ser ameaça a autoafirmação ôntica do ser humano. É a angústia frente ao destino pessoal ou coletivo: qual será o destino coletivo (no caso de sociedades coletivistas) ou o destino pessoal (em sociedades nas quais a subjetividade e a consciência de uma individualização) após a morte? Nesse caso, a perspectiva da morte anuncia a ameaça da perda definitiva da vitalidade pessoal ou coletiva. Esse tipo de angústia pode se apresentar de modo absoluto ou de modo relativo. Em termos relativos trata-se do destino pessoal; em termos absolutos, trata-se da morte universal, do fim último, da desintegração de tudo. Pessoas angustiadas com o destino e a morte são suscetíveis a respostas religiosas messiânicas ou apocalípticas. $\mathrm{O}$ apocalipcismo judaico-cristão, por exemplo, com seu ceticismo histórico conduzia pessoas ao deserto, onde a necessidade de tomar decisões, teóricas e práticas, estava reduzida ao mínimo. A fuga para o deserto era também uma tentativa de fuga da angústia. Apesar disso, mesmo em comunidades apocalípticas emergiu uma intensa criatividade narrativa ligada ao imaginário dessas comunidades.

Em segundo lugar temos a angústia da vacuidade e do absurdo. Trata-se da ameaça do caos, da ausência total de intencionalidade e 
sentido. Esse tipo de angústia se manifesta mais claramente quando o não-ser ameaça a auto-afirmação humana quanto à sua segurança de existir de modo significativo para si mesmo e para outros. Afinal, somos movidos pela intencionalidade significativa de nossos atos, gestos, sentimentos, etc. Quando já não há sentido em nossas expressões relacionais, afetivas, cognitivas ou profissionais, percebe-se a vacuidade do próprio existir, percebe-se a ausência de um sentido para as ações mais simples do cotidiano e para tudo o que realizamos na vida, na história e na cultura. Nesse caso, a "preocupação última" se expressa em termos de busca por sentido pessoal e coletivo. Pessoas acometidas por esse tipo de angústia são suscetíveis a formas de espiritualidade cínicas, oportunistas ou a discursos fundamentalistas que oferecem respostas fáceis e apressadas à dúvida, à frustração, ao tédio, à ausência de futuro e ao absurdo.

Há, ainda, um terceiro tipo de angústia, de forte cunho moral. Trata-se da angústia ligada à culpa e à condenação históricas ou transhistóricas. Essa são ameaças do não-ser à autoafirmação moral do ser humano. Nesses casos, o ser humano questiona o que fez de si mesmo, de sua liberdade finita e das decisões que tomou nas contingências de sua finitude. A angústia, nesses casos, pode levar ao desespero e à autorejeição. Pessoas acometidas por esse tipo de angústia são suscetíveis a religiões legalistas que oferecem alívio para angústia mediante a prática contínua e sistemática de ritos religiosos ou de uma ética fundamentada em discursos normativos derivados de alguma revelação. Outra resposta religiosa a esse tipo de angústia são os cultos de mistério com seus ritos de expiação e purificação ou mesmo através de formas religiosas orgiásticas.

É importante enfatizar novamente que essa tipologia não tem a intenção de distinguir objetivamente as respostas religiosas à angústia, pois a angústia é uma só. Ela apenas se manifesta diferentemente, e às vezes simultaneamente. Importa-nos compreender que a angústia emerge em virtude da ameaça do não-ser, do absurdo e do nada.

As religiões históricas, em suas diversas formas (institucionalizadas ou na forma de movimentos sectários) são sistemas que tentam oferecer respostas e algum enfrentamento à angústia. Não são, porém, as únicas possibilidades humanas. Nas expressões artísticas também podemos 
encontrar modos de dialogar, conviver ou confrontar a angústia. $\mathrm{Na}$ perspectiva tillichana, a arte expressa, transforma e antecipa. Destacamos esses verbos porque, todos aparecem nos textos tillichianos sobre a arte. A arte expressa admiração, fascínio, temor, angústia ou ansiedade diante do mundo, da vida, da morte, do absurdo e da falta de sentido; porém, a arte também transforma - ou transfigura - realidades ordinárias de modo a que apontem a partir delas, para algo que se supõe estar além delas; finalmente, a arte, de certo modo. antecipa possibilidades que transcendem aquelas já dadas. Contudo, a arte não concorre com a filosofia ou com a religião. Ela simplesmente tematiza, de modo próprio, preocupações semelhantes que estão nas bases da religião (pensamento mítico) ou da filosofia (pensamento racional).

Mas a arte não tem a pretensão de competir com os sistemas religiosos ou de substituir os discursos racionais. A arte se contenta e se satisfaz em expressar as ambiguidades da vida e de sua profundidade, transfigurar a realidade e antecipar possibilidades de superação dessa realidade, remetendo-nos a outros níveis de percepção e de construção de sentido. A arte, por não se basear em qualquer revelação sobrenatural ou na interação com forças da natureza personalizadas e divinizadas como fazem as religiões - não se propõe necessariamente a dar respostas definitivas aos dilemas humanos. A arte se contenta em interagir com a realidade, expressando-a, transformando-a, transfigurando-a e evocando múltiplas possibilidades de sentido.

\section{Existirmos - a que será que se destina?}

A partir desse pressuposto, proponho a escuta atenta da canção "Cajuína", de Caetano Veloso', sugerindo um exercício hermenêutico da mesma a partir dos temas da angústia do destino, da morte e da vacuidade de sentido.

Existirmos - a que será que se destina?

Pois quando tu me deste a rosa pequenina

Vi que és um homem lindo e que, se acaso a sina

Do menino infeliz não se nos ilumina

1 A versão original pode ser encontrada em $\underline{\mathrm{https}}$ :/www.youtube.com/watch? $\mathrm{v}=\mathrm{rmZCjp}-$ $\underline{\mathrm{nIZj} 4}$ 
Tampouco turva-se a lágrima nordestina

Apenas a matéria vida era tão fina

E éramos olharmo-nos, intacta retina

A cajuina cristalina em Teresina

(Cajuína - 1979, Caetano Veloso)

Essa canção é capaz de cativar mesmo aqueles que a ouvem pela primeira vez. Ela exige constantes releituras porque nos envolve em uma das mais antigas inquietações humanas - "existirmos - a que será que se destina?". Gravada em 1979 no álbum "Cinema transcendental", enuncia uma pergunta, ao mesmo tempo em que não oferece respostas, como a propor um enigma. Não há nela qualquer referência a Deus, deuses, orixás, orações ou a qualquer suposta força sobrenatural. Aspectos literários e musicais da canção já foram comentados por autores como Wisnick (1999) e Goulart (2003) a quem recorremos para algumas informações bastante elucidativas.

"Cajuína" é um xote rendilhado com uma sutil combinação de três elementos musicais básicos - melodia, harmonia e ritmo. O ritmo é compassado e regular; a harmonia é singela e básica; a linha melódica simples, mas eficiente. A letra é curta, com oito frases em uma só estrofe que é repetida três vezes. A cada repetição as frases são enriquecidas por variações instrumentais no arranjo, principalmente o acordeão que, no arranjo, adentra suavemente ao fundo a partir da $2^{\mathrm{a}}$ repetição como que as comentando chorosamente. É uma canção em tom menor, o que favorece uma escuta introspectiva. Ao menos no Ocidente, canções em tons menores, em geral trazem letras reflexivas que expressem sentimentos diversos como amor, saudade, angústia, ansiedade ou depressão.

Luiz Tatit ofereceu uma bela análise semiótica de canções populares a partir de duas categorias de expressão musical: a tessitura (relacionada à altura, que pode ser concentrada em durações curtas ou longas) e o andamento (relacionado à duração - acelerado ou desacelerado). Conforme essa tipologia, Cajuína é um misto de canção passionalizada e canção figurativa. É "passionalizada" porque sua tessitura traz curvas melódicas que se expandem moderadamente, ao mesmo tempo em que destacam sentimentos como que a solicitar do ouvinte uma empatia com 
os mesmos. No caso de "Cajuína", esse recurso aparece explícito no reforço da vogal "i" (destina / pequenina / sina / ilumina / nordestina / retina / cajuína / Teresina), que se destaca como uma cicatriz a reforçar tensões indicadas na letra.

Ao mesmo tempo, a canção apresenta elementos de canções figurativas - ou seja, aquelas nas quais a letra enuncia categorias temporais e especiais e a presença de interlocutores pessoais (eu-tu, eles, nós). Tatit denomina esse processo de programação entoativa da melodia e de estabelecimento coloquial do texto como figurativização por "sugerir ao ouvinte verdadeiras cenas (ou figuras) enunciativas" (TATIT, 1996, p. 21).

Esse modelo de análise compreende letra e melodia como equivalentes em uma só e mesma estrutura, evitando a irresponsável tendência de separar conteúdo e forma. Em canções passionalizadas, letra e melodia se combinam, evocando momentos reflexivos como desabafos de tensões e angústias, "como se à tensão psíquica correspondesse uma tensão acústica e fisiológica de sustentação de uma vogal pelo intérprete. [...] Afinal, a valorização das vogais neutraliza parcialmente os estímulos somáticos produzidos pelos ataques das consoantes" (TATIT, 2003, p. 9). Seria esse, conforme Tatit, o estilo mais próprio a canções que remetem a ouvinte a uma profunda reflexão existencial. Em Cajuína, temos uma tensão entre a música stricto senso e um texto poético que nunca se resolve. Uma escuta formal e rígida parece solicitar a finalização musical quando a letra traz o acento na vogal "i”. Contudo, a canção sempre traz uma sílaba a mais, como se houvesse algo ainda a ser dito... Exemplos: Desti-na / pequeni-na / si-na / ilumi-na / nordesti-na / fi-na / reti-na / teresi/na...

A frase inicial da canção (“existirmos, a que será que se destina?") levanta, abruptamente a pergunta pelo sentido da existência. Contudo, o infinitivo pessoal (existirmos) não está sozinho. É dialogado com um interlocutor não identificado que compartilha a mesma angústia ("éramos olharmo-nos"), como que a expandi-la para o coletivo. Nesse caso, a pergunta é dirigida a todos os que a escutam.

A explicação para a erupção dessa pergunta é indicada pela conjunção "pois", que aponta para outra cena - o dom de uma rosa ofertada por um "tu" ao sujeito (compositor) que a recebe ("tu me deste"). Porém, 
a cena está envolta pela lembrança de uma terceira pessoa ausente, identificada como "um menino infeliz" e sua sina.

Não há, porém, qualquer resposta para a pergunta inicial. Ela nunca é respondida, exatamente porque não pode ser respondida objetivamente. A pergunta é apenas reafirmada a cada retorno da estrofe como a reclamar uma falta, ligada à sina de um menino infeliz e à ausência de sentido para a fragilidade da vida. Para José Maria Wisnick, esse recurso nos remete a um segredo:

Talvez o encantamento enigmático de Cajuína esteja ligado ao modo como ela nos faz participar desse segredo: assim como a cajuína guarda a essência do caju em sua transparência, tendo decantado radicalmente a sua matéria, a canção nos faz ir ao núcleo emocional de um acontecimento no qual, no entanto, a história está subtraída (WISNICK, 1999, p. 196).

O texto da canção explicita três pronomes pessoais: eu (vi que és um homem lindo); tu (tu me deste a rosa pequenina), ele (a sina do menino infeliz). Tal dimensão de envolvimento orienta a pergunta inicial ("existirmos, a que será que se destina?") a uma perspectiva que atinge todos os ouvintes - Por que existimos? Ou, em termos filosóficos - porque o ser, e não o nada? Temos, então, a explicitação da condição humana diante do choque ontológico, sem qualquer referência a uma transcendência, ou à esperança de que um poder transcendente de qualquer divindade ou energia cósmica possa nos agraciar com uma resposta que dissipe a angústia da incompreensão quanto a perdas irreparáveis ou do fato de nunca encontrarmos respostas definitivamente satisfatórias para o mistério da vida.

A $5^{\text {a }}$ frase da canção com o advérbio "tampouco" ("tampouco turva-se a lágrima nordestina”) traz uma adversativa. É muito importante dar atenção às adversativas nas poesias e letras de canções. Nesse caso, "tampouco" enuncia o cerne do que Tillich compreende como "coragem de ser" - a afirmação do ser "apesar de", que equivale à afirmação de vitalidade e criatividade diante da falta de sentido. Ou seja, "apesar" da ausência de um menino infeliz, do significado de sua curta vida e da vida daqueles que o conheceram, essa a fragilidade da vida, cuja matéria é "tão fina", exige superação, resistência e coragem. Essa coragem de confrontar o não-ser é encontrada nas formas disponíveis no 
momento - uma rosa pequenina ou um licor de caju (cajuína). Não há respostas claras e objetivas. Há apenas atitudes que envolvem empatia, cuidado e solidariedade em nossa tragédia de reconhecer que a vida é precária, contingente e limitada.

Além disso, a frase "tampouco turva-se a lágrima nordestina" é melodicamente descendente. Tente entoá-la e perceberá que o timbre de sua voz vai se tornando mais grave. Ou seja, a frase não se expande, mas se interioriza, sugerindo que não são lágrimas de desespero, mas de angústia, remetendo à pergunta de todos nós. A sina do menino infeliz nos coloca diante de uma incerteza, pois o destino do menino infeliz nada nos ilumina e nada nos esclarece. Essa incerteza se expressa em dúvida (acaso, porventura, talvez...). Enfim, nada é suficiente para explicar a ausência do menino infeliz. Na ausência de resposta só restam possíveis atitudes consolatórias - a oferta de uma rosa e de um copo de licor envolto em lágrimas.

\section{Uma flor e um licor - "Cajuína” como expressão de coragem de ser}

Enquanto obra aberta, a canção não exige maiores explicações em relação ao seu locus gerador ou à sua motivação. Ela é suficiente para nos abalar, sem maiores explicações. Por isso só agora trazemos à luz um detalhe que indica sua gênese: Caetano Veloso a compôs após visitar, em Teresina, o pai de seu amigo e poeta Torquato Neto, colaborador dos tempos da Tropicália, e que se matara em 1972. Durante a visita, conversando sobre Torquato (o "menino infeliz"), Caetano se emocionou e começou a chorar muito. O próprio compositor comenta essa situação em uma entrevista. O pai de Torquato o consolou servindo um licor de cajuína e buscou uma rosa do jardim para ofertar ao compositor. A canção nasce da lembrança desse momento.

Contudo, sabemos disso apenas em virtude do relato do compositor. A não-referencialidade específica a Torquato na obra, estende o impacto da canção a todos aqueles que já experimentaram a morte de um ente querido - seja um amigo, ou um filho, filha, irmão ou irmã. Todas as mortes que acompanhamos anunciam a nossa própria morte e a pergunta pelo sentido de nossa própria vida. Assim, a canção nos abre aos terrenos da metafísica - o porquê do ser. Essa indagação desliza 
na direção da pergunta por nossa sina e pelos muitos destinos que se não pode compreender.

As lágrimas da canção lágrimas cristalinas nascidas de uma constatação, de certo modo humilhante - a vida é demasiadamente fina! Ainda assim, são lágrimas que não se turvam, não são opacas, mas são transparentes, translúcidas porque são lágrimas de pessoas acostumadas a perdas e sofrimentos. São lágrimas nordestinas, que apontam para uma angústia irrespondível, e que só pode ser compartilhada em cuidado mútuo, sorvendo a essência, o sumo de um caju esmagado para tornar-se licor; são lágrimas jorradas por quem compreende que a essência da vida, ao mesmo tempo em que é fina e frágil, também pode ser entrega, dádiva, como o caju que se oferece a ser moído para tornar-se licor. Talvez por isso a tradição cristã dê tanto valor ao trigo e à uva, moídos e transformados em símbolos de vida. A lágrima é expressão de reação à angústia, porém, na canção, não se trata de lágrimas de resignação, mas de resistência. Afinal, sempre é possível encontrar, em meio ao absurdo, pequeninas rosas ou frutas de onde se extrair um sumo.

Ademais, o sufixo "ina" na língua portuguesa aponta para diminutivos femininos ou para fragilidades - a matéria vida é tão fina quanto a rosa é pequenina. Desse modo, ilumina-se uma possível pista para o que importa em nossa curta e frágil existência - a empatia, a solidariedade e o cuidado mútuos, manifestos no dom de uma rosa e de um licor. Essas atitudes são expressões, ao mesmo tempo, de cuidado (Heidegger) e da coragem-de-ser (Tillich). Assim, o artista é iluminado pela coragem-de-ser do pai daquele menino infeliz; coragem encontrada na ausência de respostas e na densidade do nada, que ao mesmo tempo se oferece como possibilidade de força e de resistência.

\section{Considerações finais - Empatia, solidariedade e cuidado: o diferencial da arte frente ao discurso dogmático das religiões}

A arte pode nos proporcionar variadas interações entre sentimento e reflexão. Nesse caso, a arte musical nos proporciona a descrição do vazio, e das possibilidades humanas atitudes que nele se instalam. E no vazio podem se instalar duas atitudes: a primeira é o desespero e a revolta frente ao não-ser; a segunda é a coragem-de-ser que se manifesta em gestos e atitudes de cuidado mútuo, empatia e solidariedade, que 
remetem ao que há de mais nobre na singularidade do existir humano, ao mesmo tempo em que possibilitam um embate poético da angústia.

$\mathrm{Na}$ maioria dos sistemas religiosos, o "destino", a "morte" e o "sentido para a vida" são temas comuns. A busca por encontrar sentido nos acontecimentos históricos e pessoais sempre atuou poderosamente nos subterrâneos das religiões e em muitos debates filosóficos. Essas perguntas geralmente nascem de experiências interpretadas pelo ser humano como ameaçadoras. A morte é a inevitável ameaça do não-ser sobre toda existência humana, na forma de aniquilação e nada (Heidegger). A percepção de um destino inevitavelmente predeterminado relaciona-se à ameaça do absurdo (Sartre), ou seja, da destruição da estrutura do ser.

As religiões propõem diferentes explicações teológicas para o destino pessoal trilhado por cada ser humano na sua vida e as expectativas em relação ao que poderia advir após a morte - imortalidade com suas consequentes recompensas ou castigos, ressurreição, aniquilação da alma ou da identidade pessoal, absorção no Uno ou sucessivas reencarnações para que novamente se cumpra a roda do destino e se satisfaça o karma. Nas culturas de tradição monoteísta, a religiosidade popular contenta-se com a esperança de um paraíso para os fieis e alguma forma de castigo compensatório para injustos e infiéis. Em torno dessas respostas nascem formas de espiritualidade muito próprias ao mundo religioso, dependentes da estrutura de sentido doada por um ou outro sistema teológico. Mas conforme Tillich, só há uma maneira de enfrentar a angústia de tais ameaças: assumi-las corajosamente - "A coragem de ser é o ato ético no qual o homem afirma seu próprio ser a despeito daqueles elementos de sua existência que entram em conflito com sua autoafirmação existencial" (TILLICH, 1972, p. 3).

"Cajuína" se oferece como uma possibilidade de compreender o modo como a arte pode reagir, despretensiosamente, a esse tipo de angústia, a partir do vazio dela mesma - com empatia, solidariedade e cuidado-mútuo.

O silêncio das lágrimas que um dia envolveu dois homens - pai e amigo de um "menino infeliz" - bebendo em torno da memória de um morto, indicam palavras inefáveis, que não podem ser ditas. Naquele momento, apenas o sumo do caju seria capaz de iluminar seus 
olhares para vislumbrar a fina matéria-vida. Entre o amargor da perda e a doçura do licor, havia o nada: "era só olharmo-nos", simplesmente enxergar a vida e seu absurdo. E nesse momento a única atitude possível é o cuidado - uma flor e um gole de licor. O simples cuidado de ouvir, compadecer-se, chorar juntos, beber juntos apresenta-se como uma atitude de enfrentamento da angústia - se não dá pra dizer nada capaz de trazer consolo, nem explicar nada, nem oferecer qualquer resposta lógica e razoável para a sina de um menino infeliz, então resta ao menos a possibilidade de degustar o que a vida ainda oferece - um licor para amenizar o amargo da vida frente à insistente pergunta que nenhuma religião parece capaz de responder: "existirmos - a que será que se destina?"

\section{Referências bibliográficas}

ARAÚJO, Paulo, Nada, angústia e morte em Ser e Tempo, de Martin Heidegger. Revista Ética e Filosofia política, vol. 10, n. 2, 2007.

CALVANI, Espiritualidades não-religiosas. Horizonte, Belo Horizonte, v. 12, n. 35, p. 658-687, jul./set. 2014.

GOULART, Audemaro Taranto. Desconstruindo a "Cajuína" - uma leitura do texto-canção de Caetano Veloso. SCRIPTA, Belo Horizonte, v. 7, n. 13, p. 25-34, $2^{\circ}$ sem. 2003.

HEIDEGGER, Martin. Ser e Tempo. Petrópolis, Vozes, 1986.

TATIT, Luis. Semiótica da canção - a relação entre melodia e letra na canção popular brasileira. São Paulo, Escuta/USP, 1996.

"Elementos para análise da canção popular", CASA - Cadernos de semiótica aplicada, vol. 1, n. 23, dezembro de 2003.

TILLICH, Paul (1952). Art and Society. On art and architecture. New York: Crossroad, 1987. Vozes, 2005.

Teologia Sistemática. São Leopoldo; Petrópolis. Sinodal/EST,

A Coragem de Ser (Trad. Eglê Medeiros). Rio de Janeiro, Paz e Terra, 1972.

WISNIK, José Miguel. Cajuína transcendental. In: BOSI, Alfredo (Org.). Leitura de poesia. São Paulo: Ed. Ática, 1999. p. 193-219. 